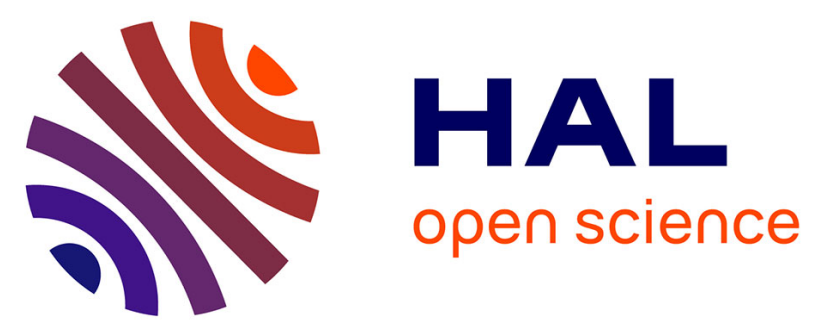

\title{
Cracking Tendency of Self-Compacting Concrete Subjected to Restrained Shrinkage: Experimental Study and Modeling
}

Ph Turcry, Ahmed Loukili, Khalil Haidar, Gilles Pijaudier-Cabot, Abdeldjelil

Belarbi

\section{To cite this version:}

Ph Turcry, Ahmed Loukili, Khalil Haidar, Gilles Pijaudier-Cabot, Abdeldjelil Belarbi. Cracking Tendency of Self-Compacting Concrete Subjected to Restrained Shrinkage: Experimental Study and Modeling. Journal of Materials in Civil Engineering, 2006, 18 (1), pp.46-54. 10.1061/(ASCE)08991561(2006)18:1(46) . hal-01006707

\section{HAL Id: hal-01006707 https://hal.science/hal-01006707}

Submitted on 27 Jul 2017

HAL is a multi-disciplinary open access archive for the deposit and dissemination of scientific research documents, whether they are published or not. The documents may come from teaching and research institutions in France or abroad, or from public or private research centers.
L'archive ouverte pluridisciplinaire HAL, est destinée au dépôt et à la diffusion de documents scientifiques de niveau recherche, publiés ou non, émanant des établissements d'enseignement et de recherche français ou étrangers, des laboratoires publics ou privés. 


\title{
Cracking Tendency of Self-Compacting Concrete Subjected to Restrained Shrinkage: Experimental Study and Modeling
}

\author{
Philippe Turcry ${ }^{1}$; Ahmed Loukili ${ }^{2}$; Khalil Haidar ${ }^{3}$; Gilles Pijaudier-Cabot ${ }^{4}$; and Abdeldjelil Belarbi ${ }^{5}$
}

\begin{abstract}
This paper presents a study on cracking risk due to shrinkage of self-compacting concrete (SCC). Cracking of SCC was investigated through a comparison of material properties, such as shrinkage, modulus of elasticity, creep, and fracture parameters, between SCC mixtures and ordinary concrete (OC) mixtures. Restrained shrinkage tests (ring tests) were also performed on the same mixtures. Numerical simulations were then used to assess the correlation between material properties and results of restrained shrinkage tests. SCC and OC were found to have equivalent shrinkage cracking tendency, provided that compressive strength is kept the same and that SCC has adequate segregation resistance.
\end{abstract}

keywords: Concrete; Compaction; Shrinkage; Creep; Cracking; Fractures; Models.

\section{Introduction}

Because of drying and chemical shrinkage, the volume of hardened concrete should decrease with time. In a structure, volume changes are hindered to a certain extent and, consequently, tensile stresses develop. Concrete structures, such as slabs and pavements, can then exhibit a high tendency for cracking.

Self-compacting concrete (SCC) is a fluid concrete cast without vibration. It is one of the most promising evolutions in civil engineering technologies. Indeed, its use results in reduction of placement costs and in enhancement of working conditions. However, SCC is suspected of presenting some disadvantages, in particular a higher shrinkage cracking tendency than vibrated concrete, also called ordinary concrete (OC). In fact, SCC mixtures are usually designed with a higher volume of paste (i.e., lower aggregate content) than ordinary concrete, which is a mix-

${ }^{1}$ Postdoctoral Student, R\&DO Institut de Recherche en Génie Civil et Mécanique GeM, UMR CNRS 6183, Ecole Centrale de Nantes, BP 92101, F-44321 Nantes cedex 3, France.

${ }^{2}$ Associate Professor, Dept. of Civil Engineering R\&DO Institut de Recherche en Génie Civil et Mécanique GeM, UMR CNRS 6183, Ecole Centrale de Nantes, BP 92101, F-44321 Nantes cedex 3, France (corresponding author). E-mail: ahmed.loukili@ec-nantes.fr

${ }^{3}$ Postdoctoral Student, R\&DO Institut de Recherche en Génie Civil et Mécanique GeM, UMR CNRS 6183, Ecole Centrale de Nantes, BP 92101, F-44321 Nantes cedex 3, France.

${ }^{4}$ Professor, Dept. of Civil Engineering, R\&DO Institut de Recherche en Génie Civil et Mécanique GeM, UMR CNRS 6183, Ecole Centrale de Nantes, BP 92101, F-44321 Nantes cedex 3, France.

${ }^{5}$ Professor, Dept. of Civil, Architectural, and Environmental Engineering, Univ. of Missouri-Rolla, 323 Butler-Carlton Hall, Rolla, MO 65409-0030. design parameter known to increase shrinkage (Bissonnette et al. 1999).

To date, data on shrinkage of SCC are controversial. On one hand, shrinkage of SCC was found to coincide well with shrinkage of OC when the compressive strength is kept the same (Persson 1999; Pons et al. 2003). On the other hand, a study on international data base showed that shrinkage of SCC was 10-50\% higher than shrinkage of OC (Klug and Holschemacher 2003). Several factors can explain these opposite conclusions, in particular the various mix-design methods and types of aggregate and/or fillers used around the world (Heirman and Vandewalle 2003).

Nevertheless, it should be emphasized that cracking risk is not only dependent on the magnitude and rate of shrinkage, but also on other material properties, such as modulus of elasticity, creep, tensile strength, and fracture resistance (Shah et al. 1998). As stated by Hammer (2003), all these properties have to be taken into account with shrinkage for assessing the cracking potential of SCC. In fact, creep in tension can be beneficial in that it in part relieves the stresses induced by other restrained movements, e.g., drying shrinkage and thermal effects. Also, the higher the volume of paste, the lower the modulus of elasticity and the higher the creep (Neville 2000). The effects of paste volume on modulus of elasticity and creep could then compensate for the effects on shrinkage, and the global result on stress generation could be negligible (Hammer 2003).

But results on viscoelastic properties of SCC are not yet abundant in the literature. In this paper, shrinkage cracking potential of SCC is investigated through a comparison of different SCC and OC mixtures, designed with various ingredients and compressive strengths ranging from 35 to $55 \mathrm{MPa}$. First, comparison is done by considering age-dependent properties governing cracking risk, such as shrinkage, viscoelastic properties, and fracture parameters. Second, shrinkage cracking is experimentally studied using a restrained shrinkage test, also called the ring test. Third, a numerical study is performed to simulate the ring test using the measured material properties.

This study, which is part of a French research program called "Projet National B@P," is based on limited sets of mixtures. It 


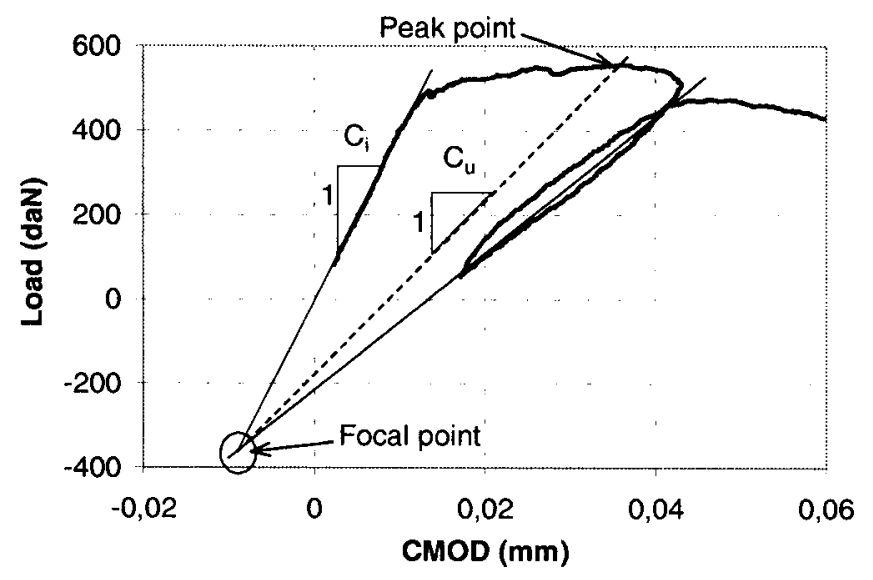

Fig. 1. Graphic determination of initial compliance $C_{i}$ and unloading compliance $C_{u}$ [method proposed by Jansen et al. (2000)]

provides preliminary evaluation of the shrinkage cracking tendency of SCC.

\section{Experimental Program}

The test procedures and materials used in the study are briefly described below.

\section{Material Properties}

Mechanical properties were measured on $110 \times 200 \mathrm{~mm}$ cylinders at 2,7 , and 28 days. Tensile strength $f_{t}$ was obtained by splitting tests. Elastic modulus $E$ was deduced from the stress and the strain measured with three extensometers during compressive tests. Before testing, cylinder specimens were stored at $20^{\circ} \mathrm{C}$ and relative humidity $(\mathrm{RH})$ of $100 \%$.

Drying shrinkage was measured on $70 \times 70 \times 280 \mathrm{~mm}$ prisms that were allowed to dry on lateral sides. After mixing, specimens were placed at $20^{\circ} \mathrm{C}$ and $\mathrm{RH}$ of $100 \%$ during $24 \mathrm{~h}$. Measurements began at the age of $24 \mathrm{~h}$ under the curing conditions of $20 \pm 1^{\circ} \mathrm{C}$ and $\mathrm{RH} 50 \pm 5 \%$. Autogenous shrinkage was measured on the same prisms, sealed by a double layer of adhesive aluminum foil.

Creep strain were measured at the age of 7 days on cylinders, $120 \mathrm{~mm}$ in diameter and $600 \mathrm{~mm}$ in length, by compressive tests. The specimens were placed in a testing room at $20^{\circ} \mathrm{C}$ and $\mathrm{RH}$ $50 \%$ and loaded to $20 \%$ of the measured 7 day compressive strength. Creep strain was deduced from the total strain of a loaded cylinder reduced by the strain (drying shrinkage) measured on an unloaded cylinder. Specific creep was obtained by dividing the creep strain $(\mu \mathrm{m} / \mathrm{m})$ and by the applied stress (MPa).

In this study, concrete fracture was studied using the two parameter model proposed by Jenq and Shah (1985). In this model, fracture resistance is characterized by the critical stress intensity factor $K_{i c}$ and the critical crack tip opening displacement $\left(\mathrm{CTOD}_{c}\right)$ along with the modulus of elasticity $E$. Fracture parameters were measured at 2, 7, and 28 days according to the RILEM recommendations (RILEM 1991a) by means of three points bending tests on $100 \times 150 \times 700 \mathrm{~mm}$ notched beams. The test procedure consists of loading the specimen by controlling the crack mouth opening displacement (CMOD). Fracture parameters were deduced from initial compliance $C_{i}$ and compliance at peak load $C_{u}$ using the procedure proposed by Jansen et al. (2000). Fig. 1

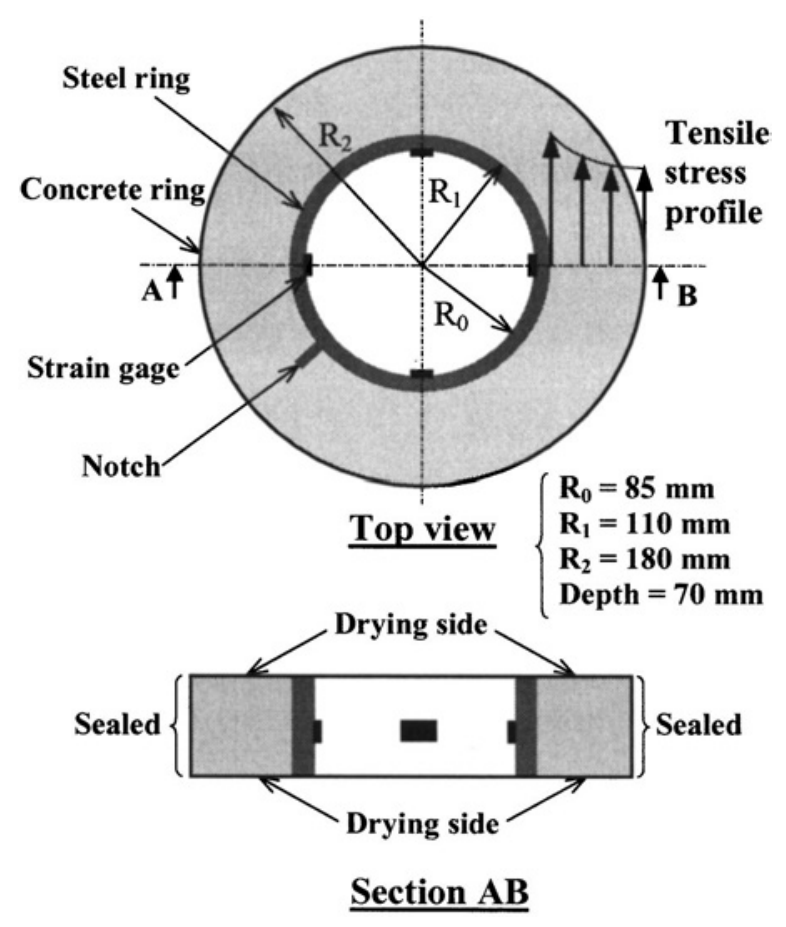

Fig. 2. Schematic of ring specimen: circumferential stress profile is indicated on top view

shows an example of load versus CMOD curve and the definition of $C_{i}$ and $C_{u}$. The beam deflection was also measured during tests. The fracture energy, i.e., the energy necessary to completely break the specimen, denoted in this work as $G_{H}$, was determined from the area under the load versus deflection curve and the crack area, according to the RILEM recommendations (RILEM 1985).

\section{Restrained Shrinkage Tests}

Metallic rings are among the widely used devices to restrain concrete shrinkage. A concrete ring is cast around a steel ring. Because steel is stiffer than concrete, volume change of concrete is prevented to a certain extent, which depends on the rings dimensions. In this study, the depth of the concrete and steel rings was $70 \mathrm{~mm}$ (Fig. 2). The inner radius of the steel ring $\left(R_{0}\right)=85 \mathrm{~mm}$, while its outer radius and inner radius of the concrete ring $\left(R_{l}\right)=110 \mathrm{~mm}$. The outer of the concrete ring $\left(R_{2}\right)=180 \mathrm{~mm}$ (so, its thickness was $70 \mathrm{~mm}$ ). The outer circumference of the concrete ring was covered by an aluminum foil to prevent moisture exchange : only the top and bottom surface could dry at a temperature of $20^{\circ} \mathrm{C}$ and $\mathrm{RH}$ of $50 \%$.

Cracking shrinkage potential was defined as the relative time at which the concrete ring cracked. In order to increase the potential of cracking at an early age, a $20 \mathrm{~mm}$ notch was placed on the outer circumference of the steel ring. Moreover, four strain gages were placed on the inner circumference of the steel ring. This measurement provides information on the stress state in the concrete.

\section{Materials and Concrete Mixtures}

Three SCC compositions, coming from different ready-mix concrete plants, were investigated (see Table 1). These mixtures were 
Table 1. Concrete Mix Proportions and Characterisation of Fresh Concrete

\begin{tabular}{|c|c|c|c|c|c|c|}
\hline & \multicolumn{2}{|c|}{ C1 mixtures } & \multicolumn{2}{|c|}{ C2 mixtures } & \multicolumn{2}{|c|}{ C3 mixtures } \\
\hline Gravel nature & \multicolumn{2}{|c|}{$6 / 10 \mathrm{~mm}$ crushed } & \multicolumn{2}{|c|}{$6.3 / 20 \mathrm{~mm}$ rolled } & \multicolumn{2}{|c|}{$4 / 12.5 \mathrm{~mm}$ rolled } \\
\hline Sand nature & \multicolumn{2}{|c|}{$0 / 4 \mathrm{~mm}$ sea sand } & \multicolumn{2}{|c|}{$0 / 4 \mathrm{~mm}$ river sand } & \multicolumn{2}{|c|}{$0 / 3 \mathrm{~mm}$ sea sand } \\
\hline Cement type & \multicolumn{2}{|c|}{ CEM2 42.5} & \multicolumn{2}{|c|}{ CEM1 52.5} & \multicolumn{2}{|c|}{ CEM1 52.5} \\
\hline Filler nature & \multicolumn{2}{|c|}{ Limestone } & \multicolumn{2}{|c|}{ Limestone } & \multicolumn{2}{|c|}{ Limestone } \\
\hline Sp type & \multicolumn{2}{|c|}{ PCP } & \multicolumn{2}{|c|}{ PCP } & \multicolumn{2}{|c|}{ PCP } \\
\hline VEA type & \multicolumn{2}{|c|}{ - } & \multicolumn{2}{|c|}{ Organic polymer } & \multicolumn{2}{|c|}{ Nano silica } \\
\hline$\left(\right.$ in $\left.\mathrm{kg} / \mathrm{m}^{3}\right)$ & SSC1 & OC1 & $\mathrm{SCC} 2$ & $\mathrm{OC} 2$ & SCC3 & OC3 \\
\hline Gravel & 825 & 1,100 & 742 & 1,030 & 790 & 1,070 \\
\hline Sand & 950 & 845 & 857 & 760 & 860 & 780 \\
\hline Cement & 330 & 280 & 350 & 350 & 350 & 360 \\
\hline Filler & 110 & 30 & 139 & 0 & 150 & 0 \\
\hline $\mathrm{Sp}$ & 4.0 & 1.2 & 6.0 & 1.7 & 5.4 & 1.0 \\
\hline VEA & 0 & 0 & 0.5 & 0 & 3.4 & 0 \\
\hline Water & 180 & 170 & 198 & 175 & 187 & 170 \\
\hline$V_{\text {paste }}\left(1 / \mathrm{m}^{3}\right)$ & 326 & 271 & 357 & 286 & 354 & 284 \\
\hline $\mathrm{W} / \mathrm{C}$ & 0.55 & 0.60 & 0.57 & 0.50 & 0.53 & 0.47 \\
\hline $\mathrm{W} /(\mathrm{C}+\mathrm{LF})$ & 0.41 & 0.55 & 0.40 & 0.50 & 0.37 & 0.47 \\
\hline Slump (mm) & - & 140 & - & 150 & - & 100 \\
\hline Spread (mm) & 680 & - & 700 & - & 680 & - \\
\hline Laitance (\%) & 5 & - & 6 & - & 15 & - \\
\hline
\end{tabular}

Note: Sp and VEA denote superplasticizer and viscosity enhancing agent, respectively. The percentage of laitance is the result of the screen stability test proposed by AFGC (2000).

made of various ingredients (cement types, nature of aggregates, etc.) and have different 28 day compressive strengths (from 35 to $55 \mathrm{MPa}$ ). Each SCC mixture was associated with an OC mixture, designed with the same ingredients. The specifications for the OC were the following : about the same 28 days strength as the associated SCC composition, a slump between 100 and $150 \mathrm{~mm}$, and a fixed paste volume. A literature review reveals that the paste volume of SCC usually ranges from about 320 to $400 \mathrm{~L} / \mathrm{m}^{3}$, while it ranges from 260 to $300 \mathrm{~L} / \mathrm{m}^{3}$ for OC (RILEM 1999, 2003). Thus, the paste volume of the OC mixtures was fixed at approximately $280 \mathrm{~L} / \mathrm{m}^{3}$, so that the difference in paste volume between SCC and OC was significant (at least 20\% more for SCC). The ingredients of SCC and associated OC mixtures are described in Table 1. Concrete mixtures were batched in a $50 \mathrm{~L}$ rotary pan mixer.

\section{Modeling of Restrained Shrinkage}

In addition to experimental working, the shrinkage cracking potential can be assessed numerically, using the measured material properties. Several models of the ring test are available in the literature (Kovler et al. 1993; Weiss et al. 2000; See et al. 2003). In this study, the model developed by Weiss et al. (2000) was chosen and adapted.

\section{Calculation of Maximum Tensile Stress in Concrete Ring}

The radial displacement $u$ of the interface between concrete and steel can be written as follows (Weiss et al. 2000):

$$
\begin{aligned}
\frac{u\left(R_{1}, t\right)}{R_{1}}-\varepsilon_{\mathrm{sh}}(t)= & \int_{0}^{t} J(t, \tau)\left[\left(1+\frac{R_{2}^{2}}{R_{1}^{2}}\right)-v\left(1-\frac{R_{2}^{2}}{R_{1}^{2}}\right)\right]\left(1+\frac{R_{2}^{2}}{R_{1}^{2}}\right) \\
& \times\left(\frac{d \sigma_{\theta}\left(R_{1}, \tau\right)}{d \tau}\right) d \tau
\end{aligned}
$$

where $R_{1}$ and $R_{2}=$, respectively, inner and outer radii of the concrete ring (Fig. 2); $\varepsilon_{\mathrm{sh}}(t)=$ free shrinkage at age $t$; $\sigma_{\theta}=$ circumferential stress in $R_{l}$ (maximum tensile stress); $J(t, \tau)=$ creep compliance; and $\nu=$ Poisson's ratio (taken equal to $0.2)$. Creep compliance $J(t, \tau)$ was expressed as

$$
J(t, \tau)=\frac{1}{E(\tau)}+\frac{\phi(t, \tau)}{E_{28}}
$$

where $E=$ modulus of elasticity at the age $\tau$ (age of loading); $E_{28}=$ modulus of elasticity at 28 days; and $\phi(t, \tau)=$ creep coefficient based on the CEB-FIP code model (1991). In this model, creep strain is assumed to be dependent on a single material property, i.e., the 28 day strength.

In his analysis, Weiss assumed $u$ to be equal to zero, that is to say that shrinkage is completely restrained. In our case, the degree of restraint is not total (otherwise, the steel ring deformation could not be measured by the strain gages). By considering equality of displacement and normal stress at the interface between concrete and steel, and the cylindrical symmetry of the problem, displacement $u$ can be also written as 


$$
\begin{aligned}
\frac{u\left(R_{1}, t\right)}{R_{1}}= & \left(\frac{1}{E_{s}}\right)\left(\frac{\left(1-v_{s}\right) R_{1}^{2}+\left(1+v_{s}\right) R_{0}^{2}}{R_{1}^{2}-R_{0}^{2}}\right) \\
& \times \int_{0}^{t}\left(1-\frac{R_{2}^{2}}{R_{1}^{2}}\right)\left(\frac{d \sigma_{\theta}\left(R_{1}, \tau\right)}{d \tau}\right) d \tau
\end{aligned}
$$

where $R_{0}=$ inner radius of the steel ring; and $E_{s}$ and $v_{s}=$ modulus of elasticity and the Poisson's ratio of the steel, respectively (Hossain and Weiss 2004). By substituting Eq. (3) into Eq. (1), the tensile stress in the concrete ring can be related to shrinkage, as follows:

$$
-\varepsilon_{\mathrm{sh}}(t)=\int_{0}^{t}[\alpha J(t, \tau)+\beta]\left(\frac{d \sigma_{\theta}\left(R_{1}, \tau\right)}{d \tau}\right) d \tau
$$

in which $\alpha$ and $\beta=$ constants calculated with elastic properties of steel and rings radii

$$
\begin{gathered}
\alpha=\frac{\left(R_{2}^{2}+R_{1}^{2}\right)+v\left(R_{2}^{2}-R_{1}^{2}\right)}{R_{2}^{2}+R_{1}^{2}} \\
\beta=\left(\frac{1}{E_{s}}\right)\left(\frac{R_{2}^{2}-R_{1}^{2}}{R_{2}^{2}+R_{1}^{2}}\right)\left(\frac{\left(1-v_{s}\right) R_{1}^{2}+\left(1+v_{s}\right) R_{0}^{2}}{R_{1}^{2}-R_{0}^{2}}\right)
\end{gathered}
$$

Eq. (4) can be solved numerically by discretizing time interval in $n$ time steps

$$
-\varepsilon_{n}=\sum_{i=1}^{n}\left[\left(\alpha J_{n, i}+\beta\right)\left(\sigma_{i}-\sigma_{i-1}\right)\right]
$$

where $\quad \varepsilon_{n}=\varepsilon_{\mathrm{sh}}(n \Delta t) ; \quad J_{n, i}=1 / E(i \Delta t)+\phi(n \Delta t, i \Delta t) / E_{28} ; \quad$ and $\sigma_{i}=\sigma(i \Delta t)$.

The solution is easily obtained by the substitution method using Matlab. Except for the creep compliance, the input data (free shrinkage, modulus of elasticity) are deduced from measurements of material properties: compressive strength $f_{c}$, Vicat setting time $t_{0}$, modulus $E$, and total shrinkage $\varepsilon_{\text {total }}$. Curves shown in Eqs. (8)-(10) are fitted to measurements

$$
\begin{gathered}
f_{c}(t)=f_{c 28}\left(\frac{\left(t-t_{0}\right)}{f_{c a}+f_{c b}\left(t-t_{0}\right)}\right) \\
E(t)=k \times\left[f_{c}(t)\right]^{1 / 3} \\
\varepsilon_{\text {total }}=\varepsilon_{\max }\left(\frac{(t-1)^{\varepsilon_{a}}}{(t-1)^{\varepsilon_{a}}+\varepsilon_{b}}\right)
\end{gathered}
$$

where $f_{c a}, f_{c b}, k, \varepsilon_{\max }, \varepsilon_{a}$, and $\varepsilon_{b}=$ constants.

It should be noted that the measured free shrinkage $\varepsilon_{\text {total }}$ is the contraction of a four-sided drying specimen while the concrete ring is a two-sided drying specimen. In order to take into account the difference of volume to surface ratio between the ring and shrinkage specimen, Eq. (11) proposed by Almudaiheem and Hansen (1989), was used

$$
\varepsilon_{\text {total }}=\varepsilon_{\infty}\left(\frac{t}{t+N}\right)
$$

with $N=20.1 \times \exp \left(0.063 \times L_{d}\right)$. In the case of the ring, the parameter $L_{d}=$ concrete ring thickness $\left(R_{2}-R_{l}=70 \mathrm{~mm}\right)$ divided by 4 , and in the case of the prism, $L_{d}=$ specimen side size (70 mm) divided by 6 (Bryant and Vadhanavikkit 1987). In this study, it is assumed that the ultimate shrinkage $\varepsilon_{\infty}$ is the same for the two specimen geometries. Thus, the shrinkage of the concrete ring $\varepsilon_{\text {sh }}$ can be estimated by Eq. (11), in which $N_{\text {ring }}$ and $N_{\text {prism }}$ are parameters $N$ of Eq. (12) for ring and prism specimens, respectively

$$
\varepsilon_{\text {sh }}(t)=\left(\frac{t+N_{\text {prism }}}{t+N_{\text {ring }}}\right) \varepsilon_{\text {total }}(t)
$$

The maximum tensile stress $\sigma_{\theta}$ in the concrete ring is deduced from Eq. (8). $\sigma_{\theta}$ can be used to calculate the inner circumferential strain of the steel $\varepsilon_{s}$ (Hossain and Weiss 2004)

$$
\varepsilon_{s}\left(R_{0}\right)=\left(\frac{\left(1+v_{s}\right) R_{0}^{2}+\left(1-v_{s}\right) R_{1}^{2}}{R_{1}^{2}-R_{0}^{2}}\right)\left(\frac{R_{1}^{2}}{R_{0}^{2}}\right)\left(\frac{R_{2}^{2}-R_{1}^{2}}{R_{2}^{2}+R_{1}^{2}}\right) \times \frac{\sigma_{\theta}\left(R_{1}\right)}{E_{s}}
$$

where $E_{s}$ and $v_{s}=$ Young modulus and the Poisson coefficient of the steel, respectively.

\section{Calculation of Cracking Age of Concrete Ring}

The age of cracking could be obtained by comparing the maximum stress in the concrete ring and its tensile strength. However, a strength versus stress criterion is known to only slightly be accurate to characterize concrete failure (Weiss et al. 2000). First, it is difficult to measure tensile strength of concrete directly. Second, a strength criterion is not able to describe size effects observed in concrete cracking. Fracture mechanics is a more powerful tool to simulate crack propagation in concrete (Băzant and Planas 1998). In this work, we used the $R$ curve approach, as proposed by Ouyang and Shah (1991). Crack propagation is expressed in terms of energy. It consists of comparing the energy release rate, or $R$ curve (fracture resistance of material), to the crack driving energy, or $G$ curve (related to the stress state). Crack is said to propagate unsteadily when the $R$ and $G$ curves plotted against crack length denoted by $a$ are tangent, i.e., when

$$
G(a)=R(a)
$$

and

$$
\left(\frac{\partial G}{\partial a}\right)=\left(\frac{\partial R}{\partial a}\right)
$$

The crack driving energy $G$ can be calculated with the maximum tensile stress in the ring $\sigma_{\theta}$ and elastic modulus $E$, using the following equation:

$$
G=\frac{\pi a}{E} g\left(\frac{a}{L}\right)^{2} \sigma_{\theta}^{2}
$$

in which $a=$ crack length; $L=$ concrete ring thickness $\left(L=R_{2}-R_{l}\right)$; and $f(a / L)=$ geometry factor. In the case of a ring geometry, $f(a / L)$ can be estimated by the following polynomial:

$$
g\left(\frac{a}{L}\right)=\sum_{i=0}^{4} A_{i} \times\left(\frac{a}{L}\right)^{i}
$$

where the coefficients $A_{i}$ were deduced from linear interpolation from coefficients published by Weiss et al. (2000) for a $R_{2} / R_{l}$ ratio equal to 1.63 .

Ouyang and Shah proposed an expression of the $R$ curve for ring geometry by approximating the ring with a edge-notched plate subjected to uniform tensile stress. This $R$ curve was used successfully to simulate the cracking age of thin concrete rings (Shah et al. 1998; Weiss et al. 2000). However, in our study, the thickness of the ring $L=R_{2}-R_{l}$ is not small compared to its mean radius $\left(R_{2}+R_{l}\right) / 2$. The tensile stress is not uniform across the ring 
Table 2. Mechanical Properties, Fracture Parameters, and Brittleness Indicators of Concrete Mixtures at Age of 28 days

\begin{tabular}{|c|c|c|c|c|c|c|}
\hline & \multicolumn{2}{|c|}{$\mathrm{C} 1$ mixtures } & \multicolumn{2}{|c|}{ C2 mixtures } & \multicolumn{2}{|c|}{ C3 mixtures } \\
\hline & $\mathrm{SCC} 1$ & $\mathrm{OC} 1$ & $\mathrm{SCC} 2$ & $\mathrm{OC} 2$ & $\mathrm{SCC} 3$ & OC3 \\
\hline$f_{c}(\mathrm{MPa})$ & 40 & 37 & 42 & 41 & 48 & 53 \\
\hline$f_{t}(\mathrm{MPa})$ & 4.0 & 4.2 & 4.0 & 4.0 & 4.8 & 4.9 \\
\hline$E(\mathrm{GPa})$ & 34 & 35 & 35 & 37 & 32 & 34 \\
\hline$K_{i c}\left(\mathrm{~N} / \mathrm{mm}^{1.5}\right)$ & 35.7 & 35.0 & 35.4 & 33.3 & 35.8 & 40.6 \\
\hline $\mathrm{CTOD}_{c}(\mu \mathrm{m})$ & 12.1 & 12.3 & 12.5 & 12.0 & 11.0 & 13.8 \\
\hline$G_{H}\left(\mathrm{~J} / \mathrm{m}^{2}\right)$ & 120 & 149 & 116 & 144 & 113 & 141 \\
\hline$Q(\mathrm{~mm})$ & 132 & 151 & 141 & 180 & 97 & 149 \\
\hline$l_{c}(\mathrm{~mm})$ & 255 & 295 & 248 & 332 & 156 & 200 \\
\hline
\end{tabular}

section and, consequently, the concrete ring cannot be approximated by a plate with uniform loading. Therefore, we chose another $R$ curve.

A parametric $R$ curve was proposed by Băzant and Planas (1998). Crack length $a$ is written by the following equation:

$$
a=a_{0}+c_{f}\left[\frac{g(x)}{2 g^{\prime}(x)}-\left(x-\alpha_{0}\right)\right]\left(\frac{2 g^{\prime}\left(\alpha_{0}\right)}{g\left(\alpha_{0}\right)}\right)
$$

where $a_{0}=$ initial crack length (notch); $c_{f}=$ critical crack extension; $g$ and $g^{\prime}=$, respectively, geometry factor and its derivative; $\alpha_{0}=a_{0} /\left(R_{2}-R_{l}\right)$; and $x=$ parameter. Energy release $R$ is written as

$$
R=G_{f}\left(\frac{g(x) g^{\prime}(x)}{g\left(\alpha_{0}\right) g^{\prime}\left(\alpha_{0}\right)}\right)\left[\frac{g(x)}{2 g^{\prime}(x)}-\left(x-\alpha_{0}\right)\right]\left(\frac{2 g^{\prime}\left(\alpha_{0}\right)}{g\left(\alpha_{0}\right)}\right)
$$

where $G_{f}=$ fracture energy. The $R$ curve is obtained by plotting $R$ from Eq. (18) versus $a$ from Eq. (17) for a series of $x$ values ( $x$ values are smaller than $\alpha_{0}$ and chosen so as $R$ remains positive). $R$ and $a$ are dependent on material parameters $G_{f}$ and $c_{f}$, which can be measured from size effect tests. $G_{f}$ and $c_{f}$ can also be deduced from fracture parameters $K_{i c}$ and $\mathrm{CTOD}_{c}$ (Ouyang et al. 1996). Based on linear elastic fracture mechanics, $K_{i c}$ and $G_{f}$ are directly related as follows:

$$
G_{f}=\frac{K_{i c}^{2}}{E}
$$

The relation between $c_{f}$ and $\mathrm{CTOD}_{c}$ is dependent on specimen geometry. Since this dependency was found by Ouyang et al. to be insignificant, $c_{f}$ is approximated by $\mathrm{CTOD}_{c}$ as follows:

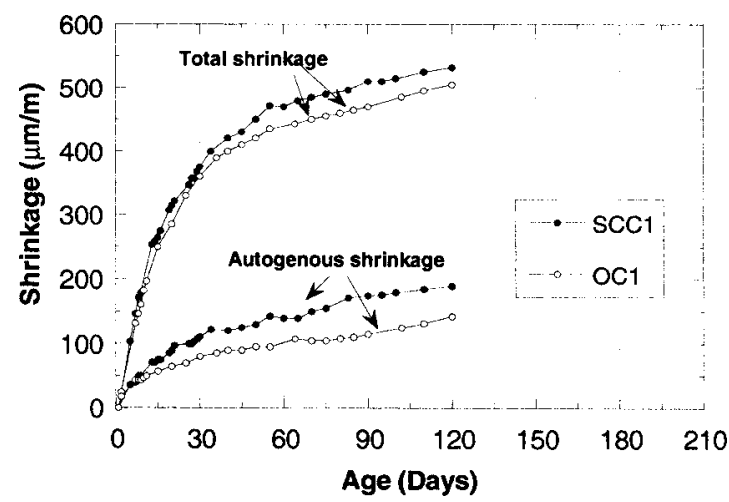

Fig. 3. Total shrinkage and autogenous shrinkage of SCC1 and OC1 mixtures

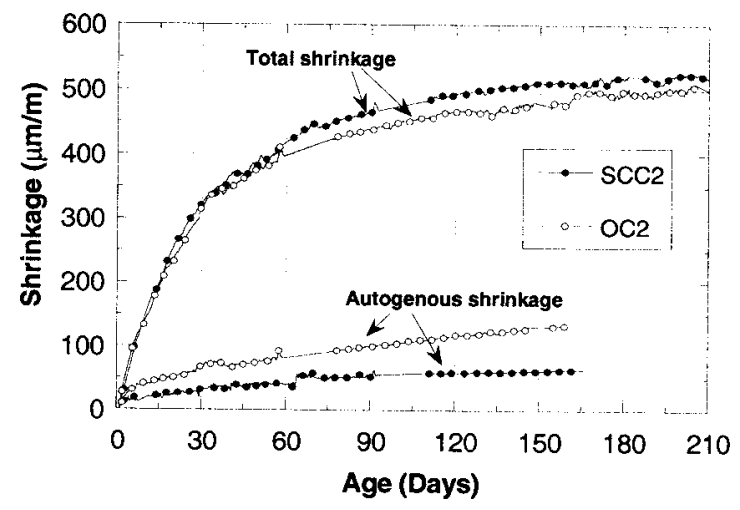

Fig. 4. Total shrinkage and autogenous shrinkage of SCC2 and OC2 mixtures

$$
c_{f}=\frac{\pi}{32}\left(\frac{E \times \mathrm{CTOD}_{c}}{K_{i c}}\right)^{2}
$$

$R$ and $a$ are written with a geometry factor $g$. In the case of ring geometry, $g$ is the same factor for the factor used for crack driving energy $G$ (i.e., $f=g$ ). The following equations provide fitting functions for $K i_{c}$ and $\mathrm{CTOD}_{c}$ :

$$
\begin{gathered}
K_{i c}=K_{i c \max }\left(\frac{t}{K_{i c a}+t}\right)^{1 / 2} \\
\mathrm{CTOD}_{c}=\mathrm{CTOD}_{c \max }\left(\frac{t}{\mathrm{CTOD}_{c a}+t}\right)^{1 / 2}
\end{gathered}
$$

where $K_{i c \max }, K_{i c a}, \mathrm{CTOD}_{c \max }$, and $\mathrm{CTOD}_{c a}=$ constants deduced from measurements.

\section{Results and Discussion}

\section{Comparison of SCC and OC Material Properties}

Table 2 provides the mechanical properties of concrete mixtures used in this study. A small difference is observed between the modulus of elasticity $E$ of SCC and OC while compressive strengths $f_{c}$ for both mixtures are the same. The modulus of elasticity of SCC is $2-8 \%$ smaller than that of OC. The difference of paste volume between SCC and OC is not large enough to create

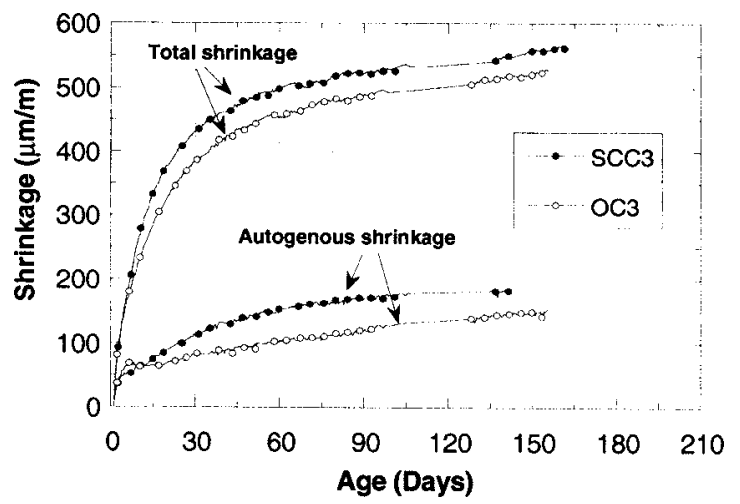

Fig. 5. Total shrinkage and autogenous shrinkage of SCC3 and OC3 mixtures 


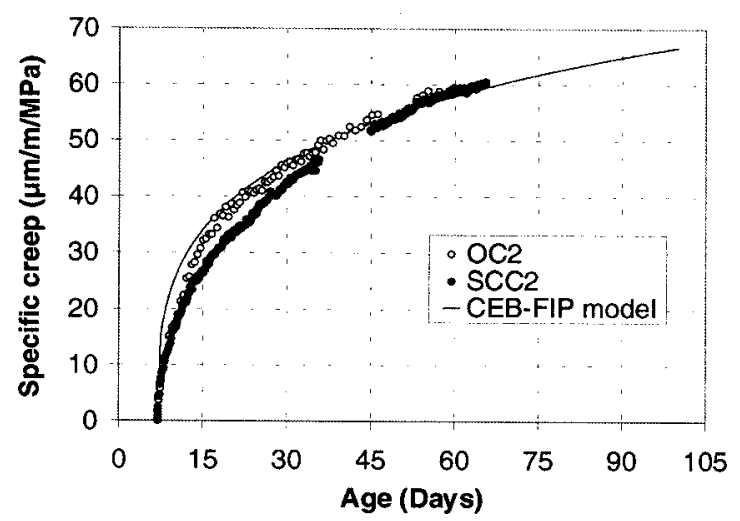

Fig. 6. Comparison of measured specific creep of SCC2 and OC2 mixtures and specific creep calculated with $C E B$-FIP model (for compressive strength equal to $50 \mathrm{MPa}$ )

a significant difference in their stiffness values. Similarly, the tensile strength $f_{t}$ is about the same for both SCC and associated OC mixtures.

Free shrinkage curves are given in Figs. 3-5. The total shrinkage of the SCC mixture is higher than the total shrinkage of the associated OC mixture. The difference is, however, relatively small. During the first 5 months, the maximum observed difference was $16 \%$ for SCC3 and OC3 mixtures. Once again, the paste volume effect can hardly explain the difference in behavior between SCC and OC, since the difference of shrinkage is small compared to the difference of the paste volume (at least $20 \%$ more for SCC). One should note that paste of SCC is designed differently from paste of OC. Thus, paste volume is a mix-design parameter that is not pertinent enough to justify any difference between SCC and OC. Water to cement (W/C) ratio and filler content may also affect shrinkage, especially autogenous shrinkage. It is known that autogenous shrinkage increases when $\mathrm{W} / \mathrm{C}$ or W/B decreases. In the case of $\mathrm{C} 1$ and $\mathrm{C} 3$ mixtures, autogenous shrinkage, as well as total shrinkage of SCC, is higher than that of OC (Figs. 3 and 4). The higher autogenous shrinkage of SCC3 compared to OC3 can be also explained by the presence of the viscosity enhancing agent (VEA) made of nanosilica. The pore structure of SCC3 could be very small due to the filling effect of

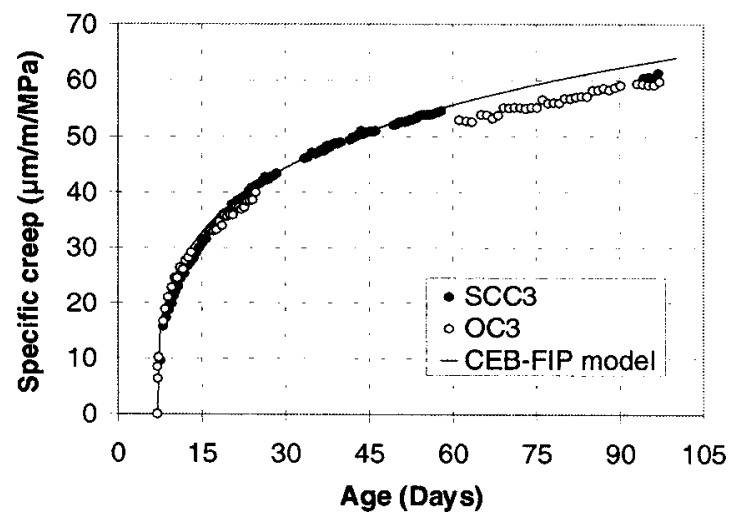

Fig. 7. Comparison of measured specific creep of SCC3 and OC3 mixtures and specific creep calculated with CEB-FIP model (for compressive strength equal to $50 \mathrm{MPa}$ )
Table 3. Tested and Modeled Cracking Ages of Concrete Mixtures (Ring Tests)

\begin{tabular}{lcccccccc}
\hline & \multicolumn{2}{c}{$\mathrm{C} 1$ mixtures } & & \multicolumn{2}{c}{ C2 mixtures } & & \multicolumn{2}{c}{ C3 mixtures } \\
\cline { 2 - 3 } Age (days) & SCC1 & OC1 & & SCC2 & OC2 & & SCC3 & OC3 \\
\hline Tested & 25 & 28 & & 27 & 27 & & 21 & 56 \\
Modeled & 23 & 25 & & 29 & 22 & & 18 & 37 \\
\hline
\end{tabular}

nanosilica, which could create high self desiccation. In the case of C2 mixtures, autogenous shrinkage of SCC is smaller than that of OC, contrary to total shrinkage (Fig. 5).

Since mix-design parameters have opposite effects on total shrinkage, interpretation of measurements with the help of mix design is somewhat challenging. Test results can also be analyzed with the help of data on SCC stability. In fact, the SCC mixture having a significantly higher shrinkage than the associated OC, i.e., SCC3, is the mixture with the highest segregation potential. In Table 1, the laitance percentage of SCC3 obtained from the screen stability test (15\%) is critical, according to the recommendations of the French Civil Engineering Association (AFGC 2000). In fact, SCC3 could be poorly homogenous, due to its low segregation resistance. It is believed that a SCC mixture with a lack of homogeneity presents poor transfer properties, and consequently high drying shrinkage. Effect of homogeneity on shrinkage should be investigated in the future.

Creep was measured on $\mathrm{C} 2$ and $\mathrm{C} 3$ mixtures, at the age of 7 days. In spite of mix-design differences, SCC and associated OC mixtures have the same specific creep strain, at least during the first 2 months of loading (Figs. 6 and 7). This is in agreement with results on creep of SCC (Persson 1999). Furthermore, a comparison of experiments with the CEB-FIP model (1991) was also done. Although test duration is relatively short, theoretical creep strain fits very well with experimental strain for both SCC and OC.

Fracture parameters of mixtures were measured at 2, 7, and 28 days (Table 2). Test results do not reveal a systematical difference in fracture behavior between SCC and OC. SCC1 and SCC2 have almost the same fracture parameters as $\mathrm{OC} 1$ and $\mathrm{OC} 2$, while $K_{i c}$ and $\mathrm{CTOD}_{c}$ of SCC3 are smaller than parameters of OC3. However, the fracture energy $G_{H}$ is significantly smaller for SCC compared to OC. This may indicate that SCC mixtures are more brittle than OC mixtures. Two indicators of brittleness can be

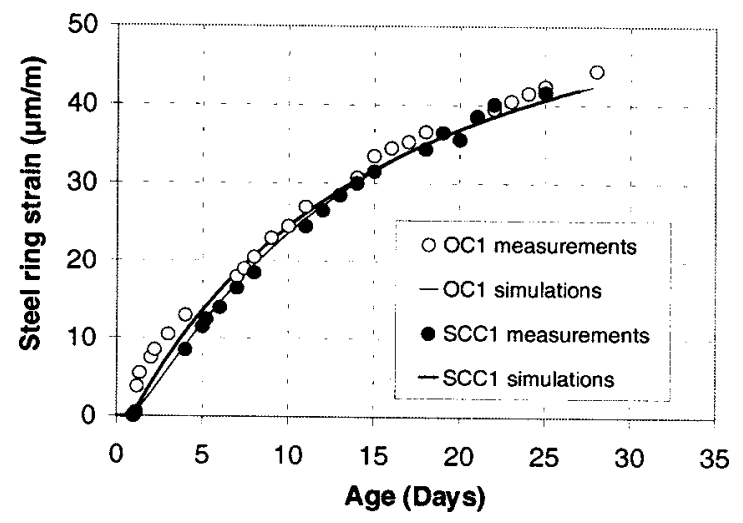

Fig. 8. Comparison of measured strain and calculated strain of steel ring for SCC1 and OC1 mixtures 


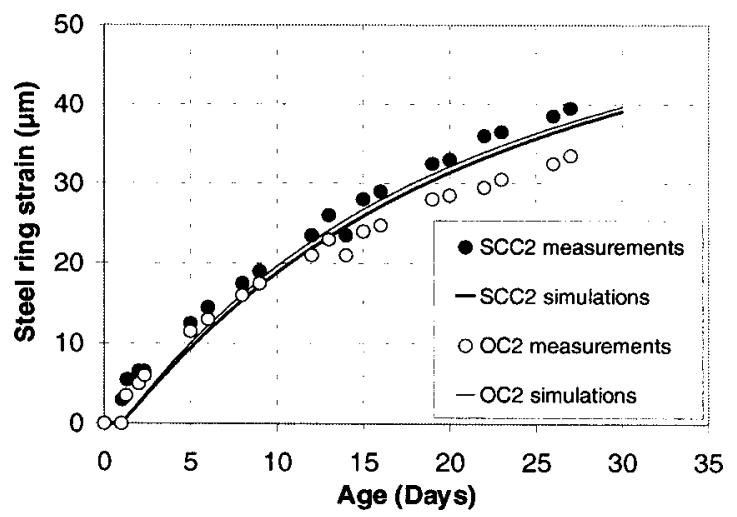

Fig. 9. Comparison of measured strain and calculated strain of steel ring for $\mathrm{SCC} 2$ and $\mathrm{OC} 2$ mixtures

determined from test data: the characteristic length $l_{c}$ proposed by Hillerborg (1976) [Eq. (23)], and the brittleness number $Q$ proposed by Jenq and Shah (1985) [Eq. (24)]

$$
\begin{gathered}
l_{c}=\frac{E \times G_{H}}{f_{t}^{2}} \\
Q=\left(\frac{E \times \mathrm{CTOD}_{c}}{K_{i c}}\right)^{2}
\end{gathered}
$$

The smaller the value of $l_{c}$ or $Q$, the more brittle is the material. According to $l_{c}$ and $Q$, the two SCC mixtures have a more brittle behavior than OC mixtures (see Table 2). This is probably due to the smaller aggregate content of the SCC, since crack propagation in a composite material, such as concrete, is affected by inclusions (aggregates) in the matrix (paste) (Pijaudier-Cabot and Băzant 1991). One should keep in mind, however, that $l_{c}$ and $Q$ are only indicators of brittleness which were revealed to sometimes be inaccurate (Zhou et al. 1995). It is regrettable that both indicators are dependent on the modulus of elasticity $E$. The smaller $l c$ and $Q$ values of the SCC mixtures are, to a certain extent, due to the smaller $E$ values. Therefore, size effect tests could be more appropriate for comparing brittleness of SCC and OC (RILEM 1991b, Băzant and Planas 1998).

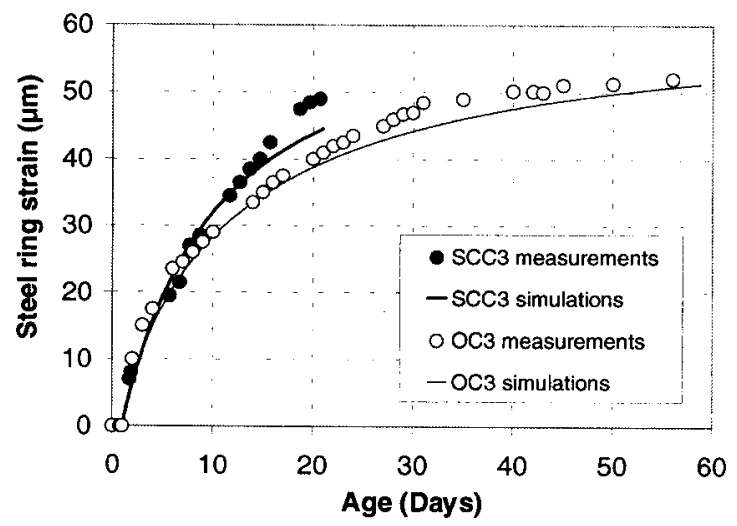

Fig. 10. Comparison of measured strain and calculated strain of steel ring for $\mathrm{SCC} 3$ and $\mathrm{OC} 3$ mixtures

Based on the material properties, it is difficult to exhibit a difference in shrinkage cracking potential between SCC and OC. In fact, as mentioned previously, some properties such as shrinkage and modulus of elasticity have opposite effects on the tensile stress evolution. This result may be favorable for SCC. But it also shows the need for other methods to evaluate cracking potential, like restrained tests or numerical investigations.

\section{Ring Test Results}

Table 3 provides the age of cracking of each mixture (average of two ring tests). SCC1 and SCC2 cracked at the same time as the associated OC mixtures. Thus, these mixtures have the same restrained cracking shrinkage potential. In Figs. 8 and 9, the strain of the steel ring is quite close for SCC and OC mixtures, which means that tensile stress increases at the same rate. This is interesting because the global behavior of concrete seems to not be affected by the minor differences in properties (a higher free shrinkage and a lower elastic modulus for SCC). Nevertheless, results on $\mathrm{C} 1$ and $\mathrm{C} 2$ mixtures can hardly be generalized. In fact, SCC3 cracked much earlier than OC3 (Fig. 10). This can be explained by both a significantly higher shrinkage at an early age and a poorer cracking resistance.

\begin{tabular}{|c|c|c|c|c|c|c|}
\hline & \multicolumn{2}{|c|}{$\mathrm{C} 1$ mixtures } & \multicolumn{2}{|c|}{ C2 mixtures } & \multicolumn{2}{|c|}{ C3 mixtures } \\
\hline & SCC1 & $\mathrm{OC} 1$ & $\mathrm{SCC} 2$ & $\mathrm{OC} 2$ & SCC3 & OC3 \\
\hline$f_{c 28}(\mathrm{MPa})$ & 40 & 37 & 42 & 41 & 48 & 53 \\
\hline$f_{c a}$ (days) & 1.12 & 1.40 & 1.03 & 1.39 & 2.51 & 2.10 \\
\hline$f_{c b}(-)$ & 0.96 & 0.95 & 0.96 & 0.95 & 0.91 & 0.92 \\
\hline$t_{0}$ (days) & 0.50 & 0.38 & 0.25 & 0.21 & 0.29 & 0.21 \\
\hline$k(\mathrm{MPa})$ & 10,070 & 10,450 & 10,000 & 10,815 & 8,700 & 9,000 \\
\hline$\varepsilon_{\max }(\mu \mathrm{m} / \mathrm{m})$ & 607 & 527 & 580 & 543 & 586 & 580 \\
\hline$\varepsilon_{a}(-)$ & 1.03 & 1.21 & 1.09 & 1.08 & 1.01 & 0.98 \\
\hline$\varepsilon_{b}$ (days) & 19.3 & 26.8 & 32.4 & 29.0 & 11.0 & 10.3 \\
\hline$K_{i c \max }\left(\mathrm{N} / \mathrm{mm}^{1.5}\right)$ & 36 & 35.5 & 35.4 & 33.3 & 35.8 & 40.6 \\
\hline$K_{i c a}$ (days) & 1.01 & 1.20 & 1.80 & 1.10 & 1.59 & 1.50 \\
\hline $\mathrm{CTOD}_{c \max }(\mu \mathrm{m})$ & 12.1 & 12.1 & 12.5 & 12.0 & 11.0 & 13.8 \\
\hline $\mathrm{CTOD}_{c a}$ (days) & 1.30 & 2.00 & 0.60 & 2.24 & 1.00 & 2.55 \\
\hline
\end{tabular}

Table 4. Coefficients of Material Properties Functions 


\section{Comparison of Experimental Results to Numerical Simulations}

Measured properties can be used to simulate ring tests and therefore to assess, numerically, the shrinkage cracking potential of concrete. Table 4 gives the coefficients of material properties functions from Eqs. (8)-(10) and Eqs. (21) and (22). Figs. 8-10 show a comparison between the strain of the steel ring calculated with Eq. (13) and the measured strain of the steel ring. It is observed that the numerical simulations are in agreement with measurements. The model provides a good prediction of steel deformation, in spite of the indirect determination of the ring free shrinkage. Furthermore, the stress relaxation due to tensile creep is calculated using the $C E B$-FIP model, an empirical model fitted on compressive creep tests. One outcome of this numerical study is maybe to show that the $C E B$-FIP model permits a correct prediction of the steel ring deformation for both SCC and OC mixtures.

Table 3 provides a comparison of measured and calculated cracking ages of $\mathrm{C} 2$ and $\mathrm{C} 3$ mixtures. Except for $\mathrm{SCC} 2$, the predicted ages are earlier than the measured one. Moreover, the difference between prediction and experimental values ranges from 7 to $34 \%$. Lack of accuracy of prediction can be explained on one hand by the relative simplicity of the model. On the other hand, measurement error for the fracture parameters $K_{i c}$ and $\mathrm{CTOD}_{c}$ was estimated at $5-10 \%$. These parameters are squared in the $R$ curve expression and, therefore, calculated $R$ curves are not very accurate. In spite of the lack of accuracy, trends in cracking age order are almost correct. Anyway, from experimental and numerical results, we cannot distinguish significantly some differences in the fracture behavior between SCC and OC.

\section{Conclusions}

Until now, most of studies on shrinkage cracking of SCC were focused on comparing the volume changes of SCC and ordinary, or vibrated, concrete $(\mathrm{OC})$. In this paper, we attempted to consider the problem as a whole by studying all the properties involved in cracking risk: shrinkage, modulus of elasticity, creep, and fracture properties.

Three SCC mixtures were compared to three associated OC mixtures, i.e., mixtures designed with the same ingredients and the same compressive strength, and with volume of paste about $20 \%$ lower. The potential for shrinkage cracking was investigated by means of material properties measurements and restrained shrinkage tests (ring tests). Numerical simulations were also performed.

When compressive strength is held constant, total shrinkage, modulus of elasticity, tensile strength, and specific creep were observed to be almost equivalent for SCC and OC mixtures designed with the same ingredients. However, although the difference is quite small, modulus of elasticity of SCC was found to be smaller than that of OC, for the tested mixtures. In the same way, total shrinkage of SCC was found to be systematically higher than that of OC.

Differences in material properties are not easy to explain with mix-design parameters. For instance, difference of paste volume could not provide a satisfactory explanation for difference in shrinkage and modulus of elasticity (which is not surprising because the paste of the SCC and the OC is designed differently). Segregation resistance of SCC may be another parameter to justify the differences in behavior, since the SCC mixture with a lack of stability presents certainly poor (i.e., nonuniform) transfer properties.

Differences in material properties between SCC and OC are minor: the risk of cracking due to restrained shrinkage may be analogous for the two types of concrete. Nevertheless, in this study, a SCC mixture showed a much earlier age of cracking in the ring test than the associated OC mixture. A restrained shrinkage test is undoubtedly a more powerful tool for assessing the potential of shrinkage cracking than direct exploitation of material properties. However, material properties can also be used for simulating restrained shrinkage. Indeed, comparison of simulations and experiments of the ring tests was proved to be quite correct. Simulations of the compressive creep tests and of the ring tests confirmed that the $C E B$-FIP model gives a relevant estimation of the creep for both SCC and OC.

In this study, few concrete mixtures were tested. Thus, one must pay attention before any generalization of the results. It is believed, however, that SCC should have the same risk of cracking due to shrinkage as OC, provided that the stability of SCC is adequate. Obviously, other concrete mixtures have to be investigated in the near future to confirm these conclusions.

\section{Acknowledgments}

The writers gratefully acknowledge the support provided by the French Research Program "Projet National B@P" and the society "VM Materiaux." They also wish also to thank P. Arora, a student from the University of New Delhi for his help.

\section{References}

AFGC. (2000). Recommendations for use of self-compacting concrete, France.

Almudaiheem, J. A., and Hansen, W. (1989). "Prediction of concrete drying shrinkage from short-term measurements." ACI Mater. J., 86(4), 401-408.

Băzant, Z. P., and Planas, J. (1998). Fracture and size effect in concrete and other quasibrittle materials, CRC, Boca Raton, Fla.

Bissonnette, P., Pierre, P., and Pigeon, M. (1999). "Influence of key parameters on drying shrinkage of cementitious materials." Cem. Concr. Res., 29(10), 1655-1662.

Bryant, A. H., and Vadhanavikkit, C. (1987). "Creep, shrinkage-size and age of loading effects." ACI Mater. J., 84(2), 117-123.

CEB-FIP Code (1991). CEB Bulletin d'Information No. 203, Paris.

Hammer, T. A. (2003). "Cracking susceptibility due to volume changes of self-compacting concrete." Proc. 3rd Int. RILEM Symp. on SelfCompacting Concrete, Reykjavik, Iceland, 553-557.

Heirman, G., and Vandewalle, L. (2003). "The influence of fillers on the properties of self-compacting concrete in fresh and hardened state." Proc., 3rd Int. RILEM Symp. on Self-Compacting Concrete, Reykjavik, Iceland, 606-618.

Hillerborg, A. (1976). "Analysis of crack formation and crack growth in concrete by means of fracture mechanics and finite elements." Cem. Concr. Res., 6(6), 773-778.

Hossain, A. B., and Weiss, W. J. (2004). "Assessing residual stress development and stress relaxation in restrained concrete ring specimens." Cem. Concr. Compos., 26(5), 531-540.

Jansen, D. C., Weiss, W. J., and Schleuchardt, S. H. F. (2000). "Modified testing procedure for the two parameter fracture model for concrete." Proc., 14th Engineering Mechanics Conf. EM2000, ASCE, Reston, Va.

Jenq, Y., and Shah, S. P. (1985). "Two parameter fracture model for concrete.” J. Eng. Mech., 111(10), 1227-1241. 
Klug, Y., and Holschemacher, K. (2003). "Comparison of the hardened properties of self-compacting and normal vibrated concrete." Proc. 3rd Int. RILEM Symp. on Self-Compacting Concrete, Reykjavik, Iceland, 596-605.

Kovler, K., Sikuler, J., and Bentur A. (1993). "Restrained shrinkage tests of fibre-reinforced concrete ring specimens: Effect of core thermal expansion." Mater. Struct., 26(158), 231-237.

Neville, A. (2000). Properties of concrete, Eyrolles, eds, France.

Ouyang, C., and Shah, S. P. (1991). "Geometry-dependent $R$ curve for quasi-brittle materials." J. Am. Ceram. Soc., 74(11), 2831-2836.

Ouyang, C., Tang, T., and Shah, S. P. (1996). "Relationship between fracture parameters from two parameter fracture model and from size effect model." Mater. Struct., 29(186), 79-86.

Persson, P. (1999). "Creep, shrinkage and elastic modulus of selfcompacting concrete." Proc., 1st Int. RILEM Symp. on SelfCompacting Concrete, Stockholm, Sweden, 239-250.

Pijaudier-Cabot, G., and Băzant, Z. P. (1991). "Cracks interacting with particles or fibers in composite materials." J. Eng. Mech., 117(7), 1611-1630.

Pons, G., Proust, E., and Assié, S. (2003). "Creep and shrinkage of selfcompacting concrete: A different behaviour compared with vibrated concrete?" Proc., 3rd Int. RILEM Symp. on Self-Compacting Concrete, Reykjavik, Iceland, 645-654.

RILEM. (1985). "Determination of the fracture of mortar and concrete by means of three-point bend tests on notched beam." Mater. Struct., 18(106), 291-296.

RILEM. (1991a). "Determination of fracture parameters $\left(K_{i c}\right.$ and CTOD $c$ of plain concrete using three-point bend tests." Mater. Struct., 23(138), 457-460.

RILEM. (1991b). "Size effect method for determining fracture energy and process size of concrete." Mater. Struct., 23(138), 461-465.

RILEM. (1999). "Self-compacting concrete." Proc. 1st Int. RILEM Symp. on Self-Compacting Concrete, Stockholm, Sweden.

RILEM. (2003). "Self-compacting concrete." Proc., 3rd Int. RILEM Symp. on Self-Compacting Concrete, Reykjavik, Iceland.

See, T. H., Attiogbe E. K., and Miltenberger M. A. (2003). "Shrinkage cracking characteristics of concrete using ring specimens." ACI Mater. J., 100(3), 239-245.

Shah, S. P., Ouyang, C., Marikunte, S., Yang, W., and Becq-Giraudon, E. (1998). "A method to predict shrinkage cracking of concrete." ACI Mater. J., 95(4), 339-346.

Weiss, W. J., Yang, W., and Shah, S. P. (2000). "Influence of specimen size/geometry on shrinkage cracking of rings." J. Eng. Mech., 126(1), 93-101.

Zhou, F. P., Barr, B. I. G., and Lydon, F. D. (1995). "Fracture properties of high strength concrete with varying silica fume content and aggregates." Cem. Concr. Res., 25(3), 543-552. 